\title{
Cheap and Effective System for Parking Avoidance of the Car Without Permission at Disabled Parking Permit Spaces
}

\author{
Kohei Arai ${ }^{1}$ \\ Graduate School of Science and Engineering \\ Saga University \\ Saga City, Japan
}

\begin{abstract}
Cheap and effective system for parking avoidance of the car without permission at Disabled Parking Permit: DPP spaces is proposed. The proposed system is validated through some experiments. Multiple methods for detection of car in the DPP space using ultrasound sensors, Near Infrared: NIR cameras, RFID writer and reader with IC card, IC chip and IC tag as well as ETC system and GPS receiver are proposed. It is found that these proposed car detection systems work well. Furthermore, it is effective if more than two systems out of the proposed car detection systems are used for avoid car parking without permission.
\end{abstract}

Keywords-Disabled Parking Permit; ultrasound sensor; Near Infrared cameras; RFID writer and reader with IC card; IC chip and IC tag; ETC system; GPS receiver

\section{INTRODUCTION}

A disabled parking permit is known as a handicapped permit, disabled placard, disabled badge and "Blue Badge" in the European Union: EU under the Chronically Sick and Disabled Persons Act which was estiblished in $1970^{1}$. The blue badge is displayed upon parking a vehicle carrying a person whose mobility would be otherwise significantly impaired by one or more of age, illness, disability or infirmity. Since 2000, all general disabled parking permits in the European Union: EU have been standardized to a common style and blue color, leading to the officially-used designation "Blue Badge".

In Ireland, Disabled Persons' Parking Permits: DPPP are issued by the Disabled Drivers Association of Ireland while United Kingdom provided a service that covers country wide customized maps for Blue Badge Holders with different base colors reflecting council's policies on Blue Badge Holder's parking $^{2}$. The standard scheme only generally applies to onstreet parking and is outlined on the Roads Service Northern Ireland website ${ }^{3}$.

In the United States, reserved spaces are mandated by the Americans with Disabilities Act Accessibility Guidelines ${ }^{4}$. 26 states adopted Disability Parking Permit: DPP systems. Four states include deafness, and only two states (Virginia and New

\footnotetext{
${ }^{1}$ http://en.wikipedia.org/wiki/Disabled_parking_permit

${ }^{2}$ https://www.gov.uk/apply-blue-badge

${ }^{3}$ http://www.nidirect.gov.uk/roads-service

${ }^{4}$ http://en.wikipedia.org/wiki/Americans_with_Disabilities_Act_of_1990
}

York) include mental illness or developmental disabilities. Parking spaces reserved for the disabled are typically marked with the International Symbol of Access: ISA, though in practice, the design of the symbol varies widely. If traveling from other countries, requirements to obtain a parking permit vary from state to state. Some states will honor other country permits, while others require application as a visitor/tourist.

Parking for the handicapped driver in New York City is limited to those with New York City-issued handicapped placards 5 . No other handicap placards are recognized as valid. In 1997 a woman with multiple sclerosis using a wheelchair was similarly issued a ticket while parking in New York City for displaying a non-NYC issued handicap placard. The abuse and/or misuse of disabled parking permits has been identified as a major problem in the US, with some estimates indicating the majority seen on the street are used or obtained fraudulently. Disabled persons who hold parking permits but have invisible disabilities may be difficult to tell apart from fraudulent permit users. Some conditions which make a disabled parking permit necessary are invisible without medical training. An injury or illness which causes an individual to be unable to walk very far may not be obvious, and a prosthesis or healing injury may be hidden under clothing. On occasion, suspicion of fraud has led to hostility against legitimate permit holders.

In Australia, disabled parking permits are provided under the Australian Disability Parking Scheme, which was established in September 2010 to harmonize disability permits across Australia ${ }^{6}$. Disabled parking permits are applied for through state and territory organizations, and rules for eligibility differ among jurisdictions.

In Japan, Saga prefectural government started DPP system in $2006^{7}$. They provide DPP for more than 10 thousand disabled persons, pregnant, elderly peoples, etc. DPP is just for disabled persons while DPP Plus One: DPPPO system

\footnotetext{
${ }^{5}$ http://www.nyc.gov/html/dot/html/permits/pppdinfo.shtml\#nyc_permit

${ }_{7}^{6} \mathrm{http}: / /$ www.disabilityparking.gov.au/

http://www.pref.saga.lg.jp/web/kensei/_1363/sougoukeikaku2011/2011_Catal ogue_eg/4_3_eg.html
} 
provides another parking space for pregnant, elder persons and the others who need wheel chair. 1651 of parking lots are prepared DPP spaces already in Saga prefecture which include hospitals, Group Homes, shopping malls, etc. already. The DPP system is expanding to the other prefectures and cities. Currently, 30 prefectures and three cities adopted DPP system.

One of the biggest problems on DPP system is avoidance of car parking without permission. Due to the fact that the DPP spaces are shared by the cars without parking permission, the cars with permission cannot park their cars at the DPP spaces [1]. The paper proposes a DPP system allows avoiding car parking without permission.

In the next section, the proposed DPP system which allows avoiding car parking without permission is described followed by some experimental results. Then conclusion is described together with some discussions.

\section{PROPOSED DPP SYSTEM}

\section{A. System Configuration}

Process flow of the proposed DPP system is shown in Figure 1. The proposed DPP system has to detect cars in the designated DPP spaces. Also it has to distinguish the cars between with and without permission. After the system detects the cars without permission at the DPP space, some cautions are provided to such cars. These are components of the proposed system.
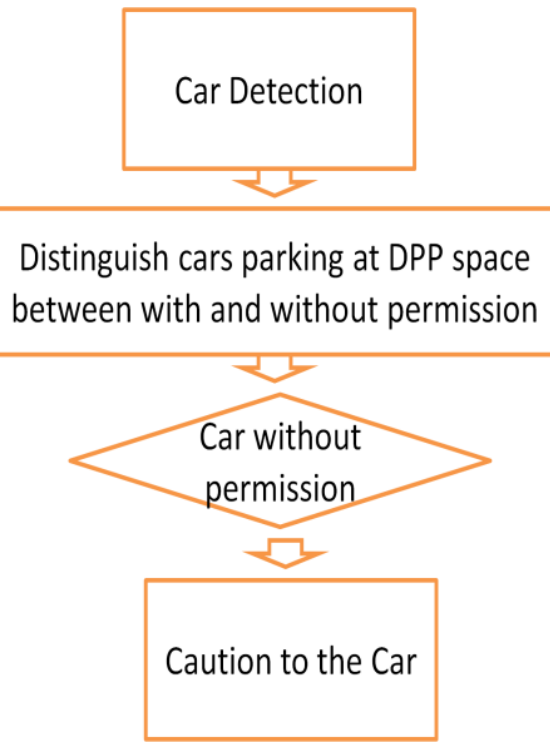

Fig. 1. Process flow of the proposed DPP system

Meanwhile, Figure 2 shows system configuration of the proposed DPP system. There are some alternatives for car detection system, caution system. Also, there are some candidates for caution system.

Hardware configuration includes, NIR LEDs, NIR camera, Ultrasonic sensor, RFID reader and writer, IC card, IC chip, GPS receiver, Mobile phone, ETC system, Tablet terminal or PC.

\section{B. Car Detection Systems}

Cars have to be detected in day time and night time as well as in all weather conditions. Therefore, car monitoring cameras have to be visible and infrared cameras. Near Infrared: NIR cameras would be appropriate for car monitoring in day and night time and all weather conditions. NIR cameras require NIR light source. Otherwise, Signal to Noise ratio: SNR of NIR camera images would not be enough to recognize the plate number in concern. There are some commercially available NIR camera systems with NIR Light Emission Diodes: LEDs. It is not always that NIR camera system can detect cars in the designated DPP space due to heavy rain, or snow. Ultrasound sensor would work for car detection in such cases.

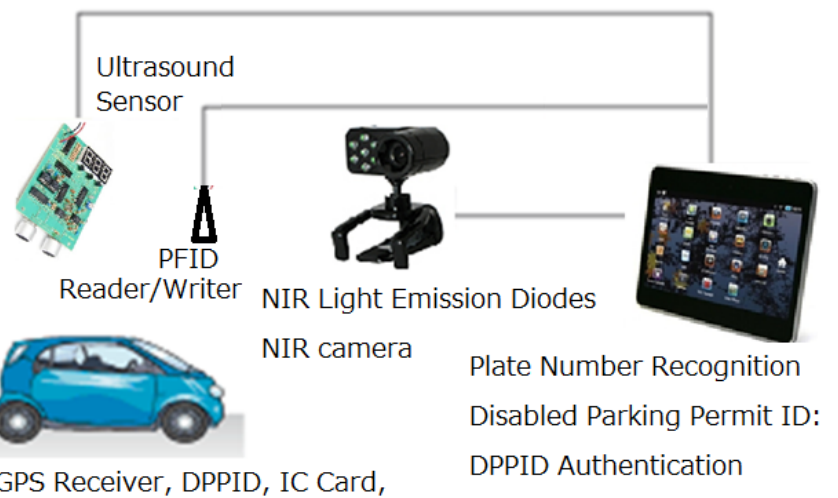

IC Chip, ETC system,

Sound, Flashing light, etc. for causion to the drivers without DPPID

Fig. 2. System configuration of the proposed DPP system

On the other hand, there is another alternative. Using Radio Frequency Identification: RFID reader and writer, it is possible to identify DPPID holders. DPPID, in this case, is written in the specific IC card for DPPID, or other existing cards with IC chip for DPPID.

Another possibility of car detection is to use Electronic Toll Collection System: ETC system ${ }^{8}$ for toll fee payment system. If the car equipped ETC system, then ETC signal can be read by the ETC receiving system.

GPS receiver is another possibility. Now a day, GPS receiver is available for almost cars. Even for the car without GPS receiver, it is possible to acquire their location data through GPS system containing in the mobile phones. Now a day, GPS receiver is equipped in the mobile phone in standard basis. If the car drivers with DPP registered to the ministry of transportation, then their location data can be available to acquire. Therefore, it is possible to find the car drivers are situated at the DPP space because the car drivers' mobile phones tell their location with a few meters of location estimation accuracy.

${ }^{8}$ ETC uses $5.8 \mathrm{GHz}$ center frequency of ISM band which is common frequency band for armature wireless communications. Data rate is $1024 \mathrm{kbps}$ based on Dedicated Short Range Communication: DSRC with ASK. 


\section{Distinguish Cars Which Park DPP Space Between With and Without Permission}

After the car detection, cars with and without DPP have to be distinguished each other. For the case of NIR camera monitoring system for car detection, plate number has to be recognized and then compare to the previously registered plate numbers in the DPP car plate numbers.

For the case with RFID reader and writer, it is possible to identify car drivers with DPP recorded on IC card or IC chip easily. On the other hand, it is possible to identify the cars with ETC identification code if the cars are registered as DPP holder with ETC identification code. Meanwhile, previously registered car drivers for their location identification with GPS receiver can be distinguished as DPP holder.

\section{Caution to the Car Without DPP}

Next thing we have to do is make a caution to the car in the DPP space without DPP. There are three possible methods for making caution.

1) Caution with sound

2) Caution with flash light

3) Upload the photos of cars parking at DPP space without permission to YouTube

If car which is parking in DPP space without permission is found, a caution has to be announced to the car drivers with sound, "Do not park your car here because you do not have Disabled Parking Permit" or some other words. It is much more polite way to make caution with flash light. The third method is to avoid car parking without permission by uploading photos their cars with recognized plate number on YouTube. They are shamed when they look at the photos.

\section{E. Hardware Configuration}

NIR camera with NIR LED of NET COWBOY DCNCR131 camera is used. Major specification is as follows,

Interface: USB 1.1

OS: Windows2000/XP

Cable length: $1.5 \mathrm{~m}$

Resolution (Pixel Size): 11280×1024

Dimension: $52(\mathrm{~W}) \times 65(\mathrm{D}) \times 70(\mathrm{H}) \mathrm{mm}$

Weight: $105 \mathrm{~g}$

There are 7 NIR LEDs just beside the camera mount of optical entrance.

ACER computer ASPIRE 5572 Series Core Duo T2050 1.6 GHz CPU and $1 \mathrm{G}$ of RAM is used for image processing, sound output, flashing light, ultrasonic sensor control, and camera control.

Principle of ultrasonic sensor is shown in Figure 3.

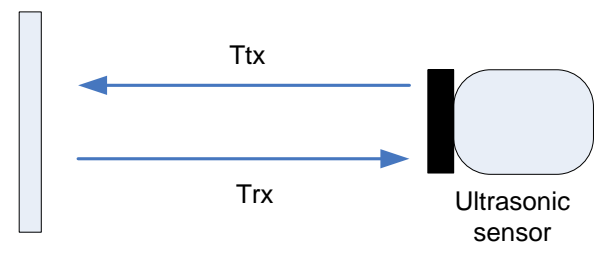

Fig. 3. Ultrasonic sensor, distance is measured by converting half of Ttx transmitting time and $\operatorname{Trx}$ receiving time
Ultrasonic sensor of T40-16 is used for car detection. Major specification of the sensor is as follows,

Frequency $(\mathrm{kHz}) 40$

Sound pressure level $(\mathrm{dB}) 115<$

Sensitivity $(\mathrm{dB})-64<$

Dimension: Diameter 16.2, Height 12.2, Interval 10.0

Measurable distance: $0.4-4 \mathrm{~m}$

Unit of the measured distance: $\mathrm{cm}$

Meanwhile, the MOD-RFID125 is used for reading IC card and/or IC chip for DPPID This RFID reader is USB type of RFID station, able to read Manchester-encoded 64-bit

EM4102 tags with 64 periods of carrier frequency per data bit. All the complexity of RFID tag detection, verification and decoding are handled by MOD-RFID125. After it strips the header and the checksums user is given the 40-bit ID of the transponder tag. Major specification of the RFID reader is as follows,

Supports Manchester-encoded 64-bit EM4102 RFID tags with 64 periods of carrier frequency per data bit;

Base RFID frequency $125 \mathrm{kHz}$;

USB port connection to PC;

Standard 5V UART 9600, 8N1 connection to user microcontroller boards;

Three modes of operation, easily changed by pressing the button;

- USB HID keyboard emulation mode;

- USB CDC serial port emulation mode;

- UART connection mode;

Simple command-line interface in USB CDC and UART modes for configuration and data acquisition;

Two LEDs indicating device status and tag presence;

Support for continuous and periodic RF scanning to better suit user power requirements;

Ships with default mode USB HID and default configuration: continuous read, scan always, one report per second, LEDs activated;

\section{EXPERIMENTS}

\section{A. Ultrasonic Sensor}

Experiments are conducted for assessment of distance measurement accuracy of the ultrasonic sensor used. Some objects are put in front of the sensor with varies distances, 0$3 \mathrm{~m}$. Ultrasonic sensor use PING type parallax product and microcontroller AT89S51 as processing data (convert from time value to distance output). Graph of accuracy sensor is shown in Figure 4.

Elevation angle is an important parameter for distance measuring accuracy of the sensor. This implies that the accuracy depends on sensor beam angle or width. Narrow beam allows a good accuracy because it is not affected due to influence with any disturbance. This experiment is conducted by measure elevation angle from $0 \mathrm{~cm}$ until $3 \mathrm{~m}$. Figure 5 shows the relation between distance and elevation angle. Also, Figure 6 shows experimental results of the relation between elevation angle and distance measuring accuracy. Above portion of the graph shows the relation of distance versus 
angle while below portion of graph shows the relation between the distances versus distance elevation.

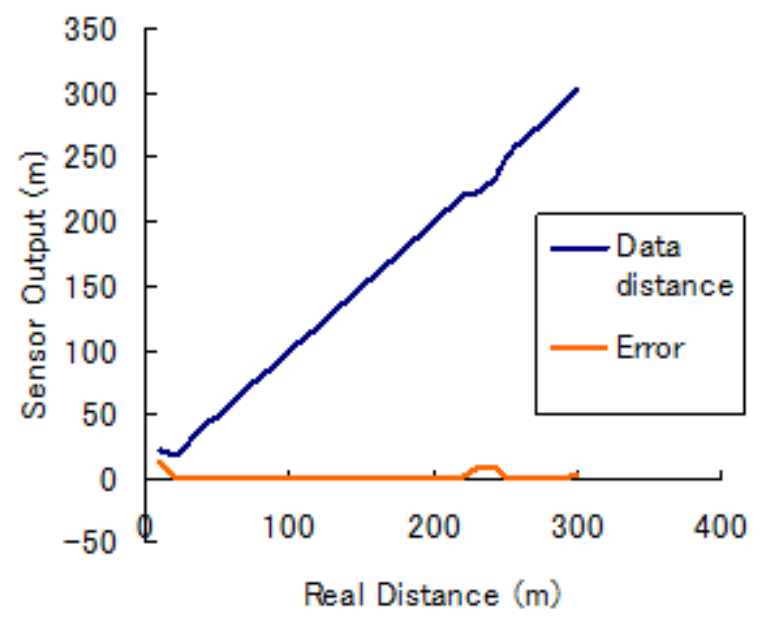

Fig. 4. Experiment of ultrasonic accuracy. This shown that minimum distance is around $3 \mathrm{~cm}$ and maximum distance is $3 \mathrm{~m}$. This range is appropriate for detect the object.

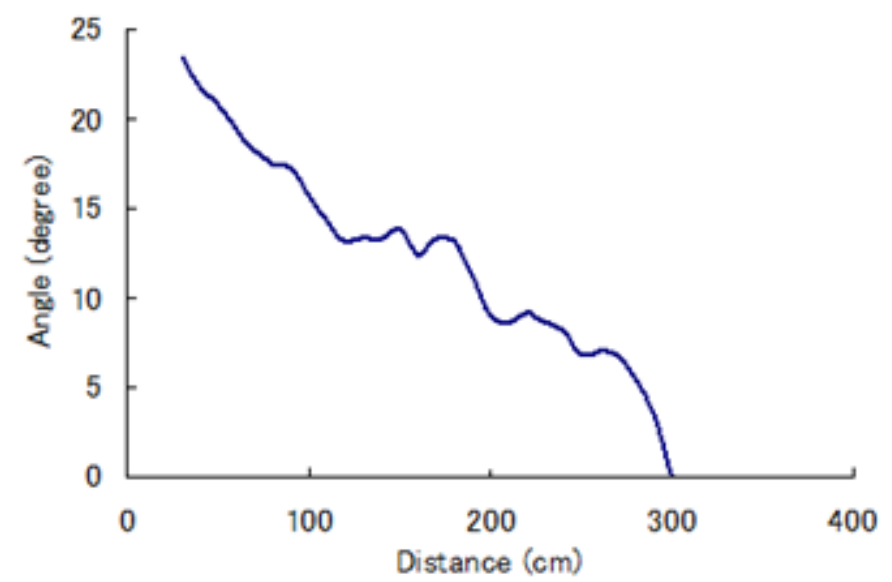

Fig. 5. Relation between distance and elevation angle.

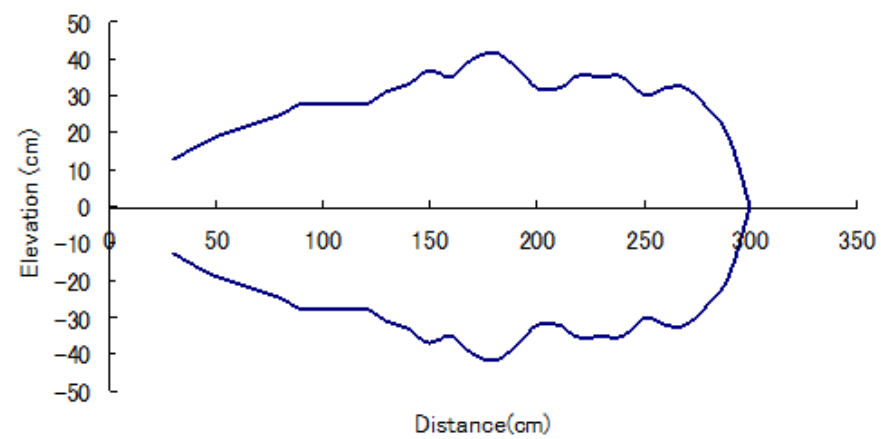

Fig. 6. Experiment of Elevation angle. Top side is distance versus angle, and bottom side is distance versus distance elevation.

Data is stored into computer by using USB communication. Results show that averaged processing time is $568.658 \mathrm{~ms}$. Figure 7 also shows processing time of ultrasonic sensor. It looks that it takes longer time than the others.

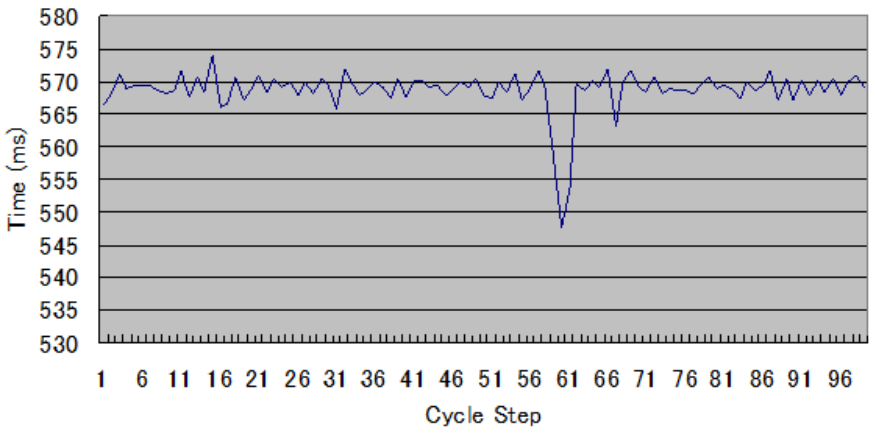

Fig. 7. Processing time of ultrasonic sensor.

\section{B. Number Plate Recognition}

Figure 8 shows an example of the acquired image of the car which is parking at the parking lot. The example image is acquired in day time. The car in concern is situated in shaded area. Then the image is binarized with appropriate threshold. Figure 9 (a) shows the enhanced image while Figure 9 (b) shows binarized image with the determined threshold with histogram which is shown in Figure 9 (c).

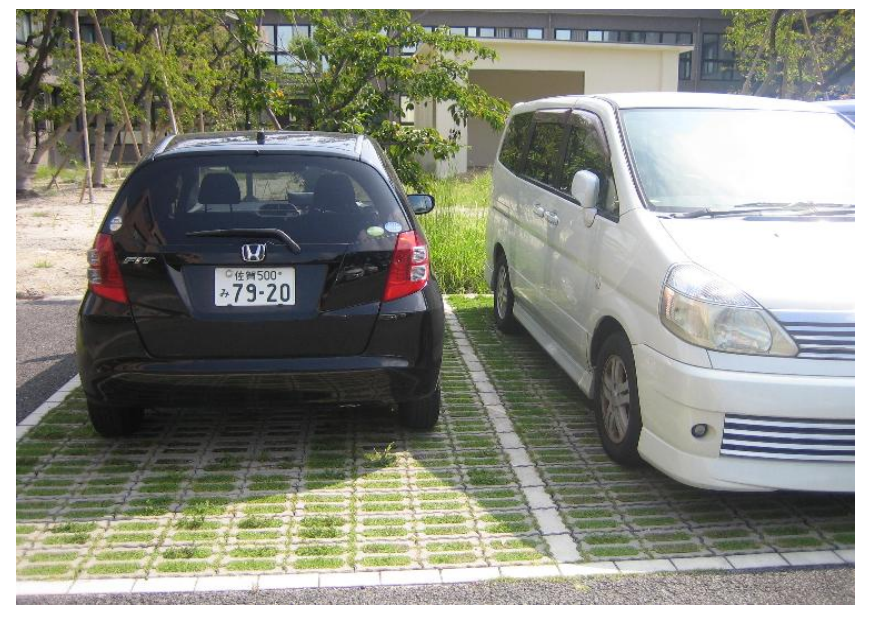

Fig. 8. Example of the acquired image of the car which is parking at the parking lot

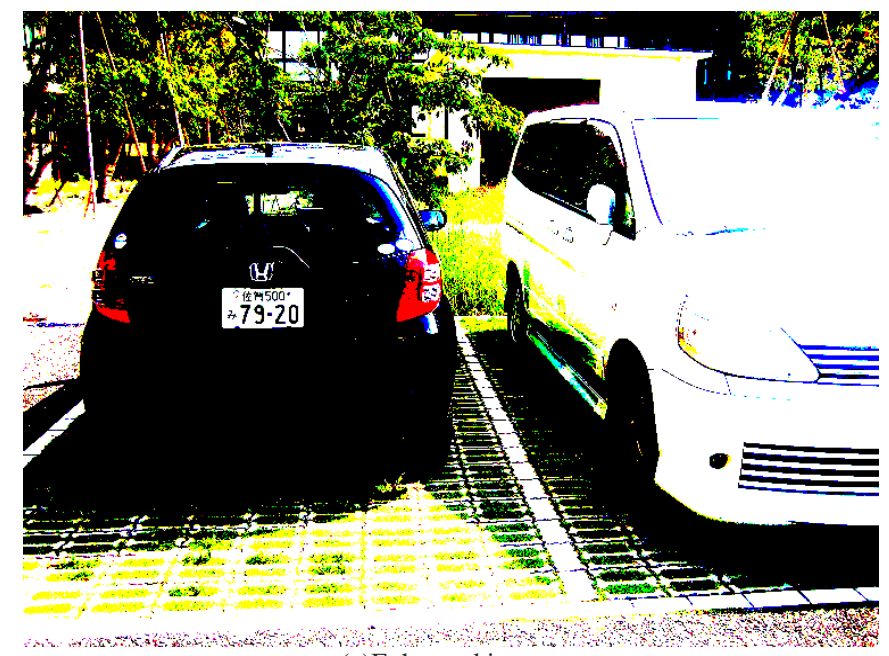

(a)Enhanced image 


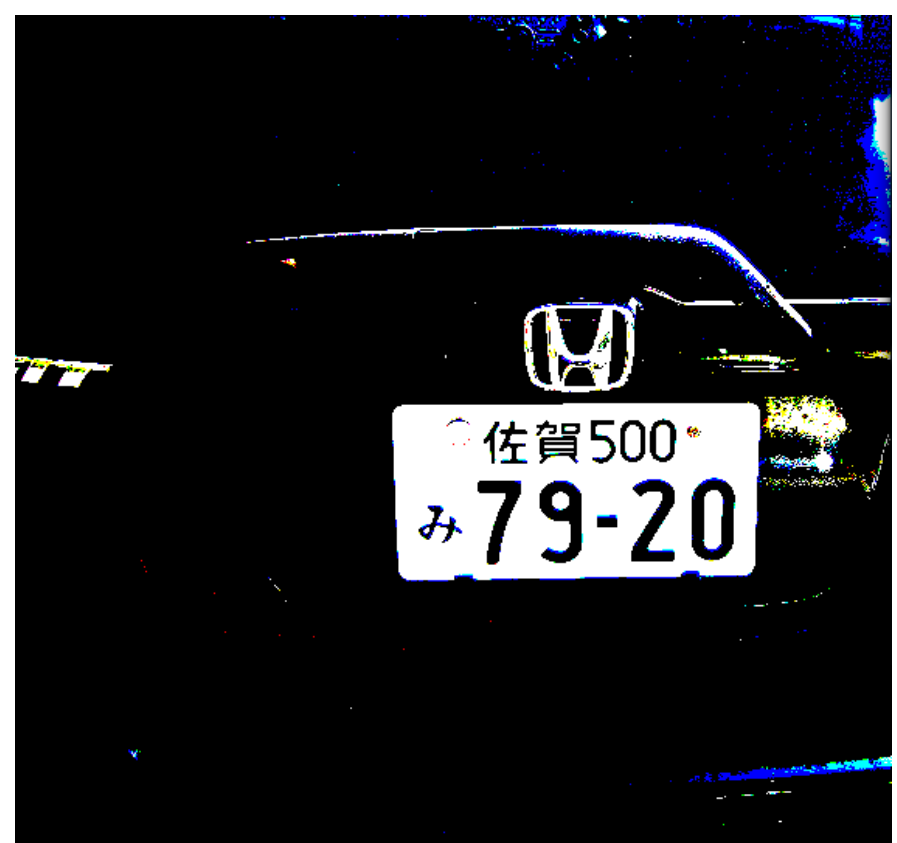

(b)Binarized image

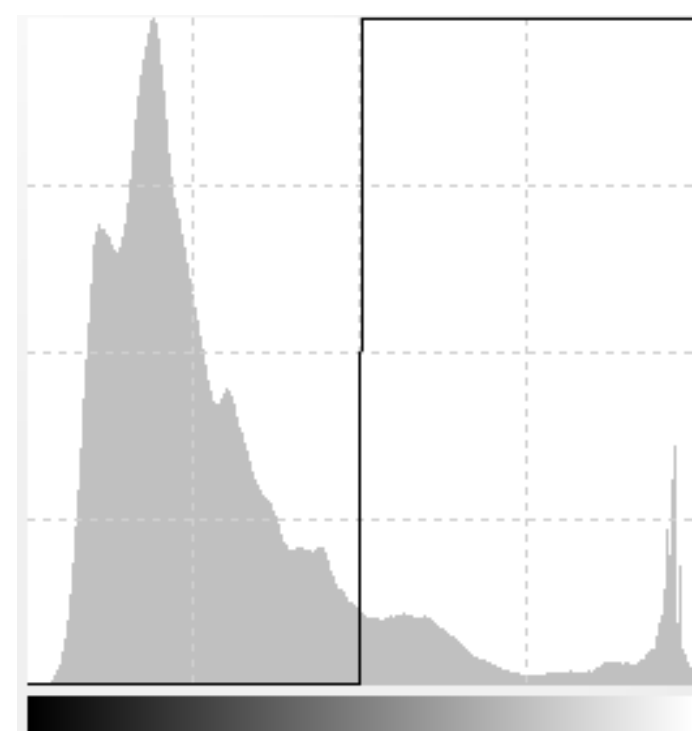

(c)Histogram of the original image

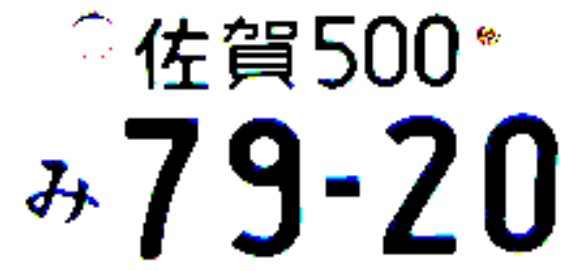

(d)Extracted image of the number plate in concern

Fig. 9. Processed images of day time acquisition before Optical Character Recognition: OCR

Then the number plate is extracted through blob likeness operator which is shown in Figure 9 (d)

These are same things for the acquired images in night time. The acquired image in night time is binarized with appropriate threshold. Figure 10 (a) shows the binarized image with the determined threshold with histogram which is shown in Figure 10 (b). Also, Figure 10 (c) shows the extracted number plate for OCR.

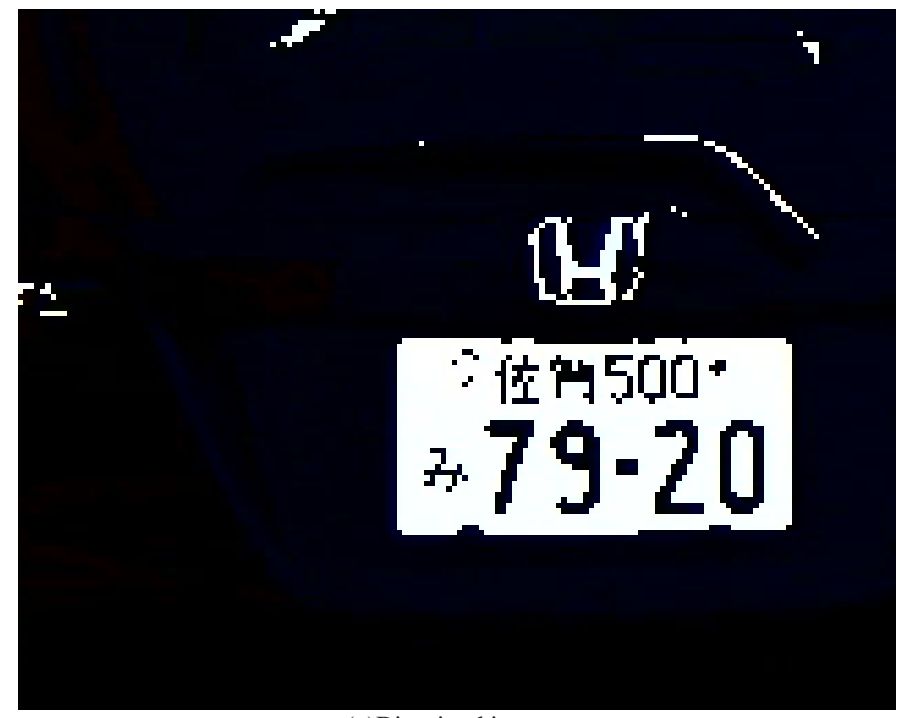

(a)Binarized image

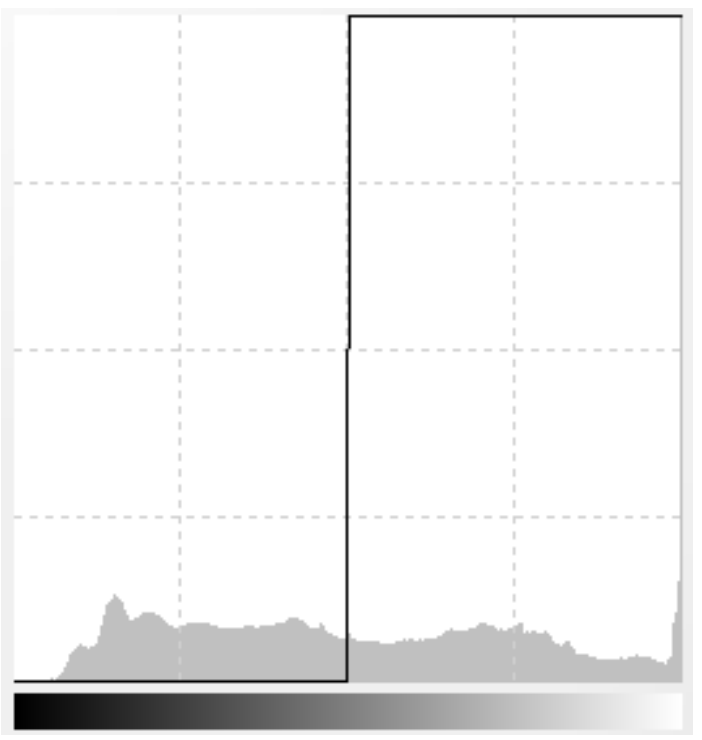

(b)Histogram of the original image

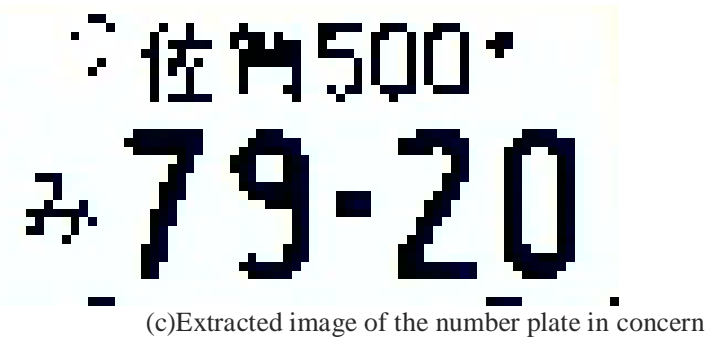

Fig. 10. Processed images of night time acquisition before Optical Character Recognition: OCR

The images which are acquired in night time are dark and less contrast comparing to those which are acquired day time. The binarized images, however, are still recognizable for OCR. Using "nhocr" of OCR engine for Japanese language ${ }^{9}$, four

${ }^{9}$ http://maggie.ocrgrid.org/nhocr/ 
digits of numerical characters are almost perfectly recognized. Comparison of the current plate number to the previously registered plate number is made for the four digits of numerical characters. Therefore, the first Kanji characters and small numerical numbers and small Hiragana character can be omitted.

\section{Location Estimations of the Registered Cars}

The registered cars are available to estimate their location by using GPS system which is equipped their mobile phones. Figure 11 shows one example of the location of the registered car on a map.

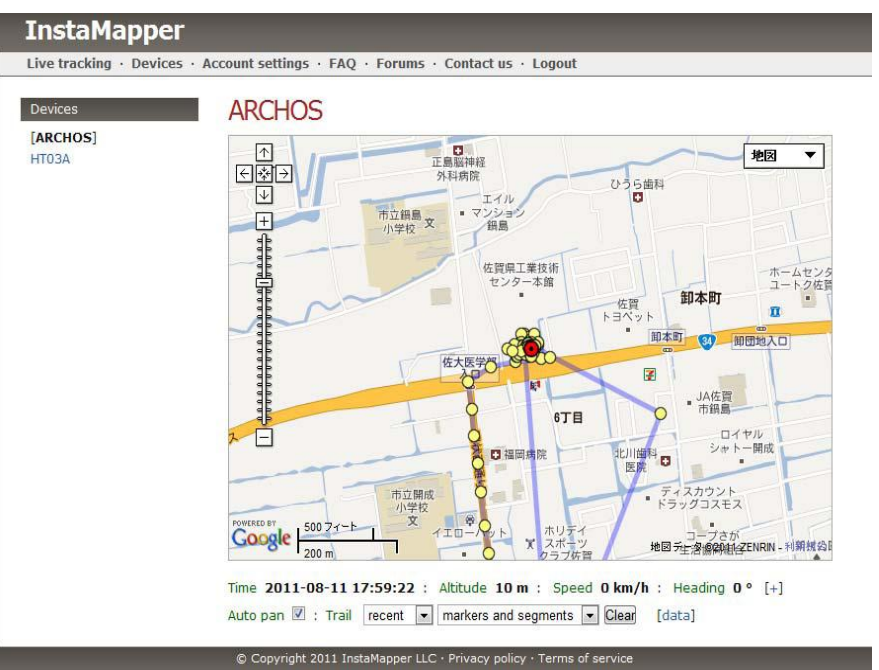

Fig. 11. Example of the location of the registered car on a map.

The locations of the registered cars are updated every one second with a couple of $\mathrm{m}$ of location estimation accuracy. The time interval of 1 second is good enough. Yellow dots show the location with every one second time interval. Meanwhile, a couple of $\mathrm{m}$ of location estimation accuracy would be marginal. The estimated location is compared to the location of DPP space. If these are matched, then the car in the DPP space is permitted. If cars are detected in the specific DPP space by ultrasonic sensor, and if there is no indication of registered car in the DPP space, caution is made to the car.

\section{CONCLUSION}

Cheap and effective system for parking avoidance of the car without permission at Disabled Parking Permit: DPP space is proposed. The proposed system is validated through some experiments. Multiple methods for detection of car in the DPP space using ultrasound sensors, Near Infrared: NIR cameras, RFID writer and reader with IC card, IC chip and IC tag as well as ETC system and GPS receiver are proposed. It is found that these proposed car detection systems work well. Furthermore, it is effective if more than two systems out of the proposed car detection systems are used for avoid car parking without permission.

It is found that considerable combination of more than two methods proposed here would be useful and effective to avoid the car parking without DPP permission.

\section{ACKNOWLEDGMENT}

The author would like to thank Professor Dr. Masaru Kiyota of Saga University for his valuable discussions we have had through research works. Also, the author would like to thank Dr. Steven Ray Sentinuwo for his efforts to conduct experiments and simulations.

\section{REFERENCES}

[1] Arai, K, Introducing IT technologies to Disabled Parking Permit, Saga University Organized Sympojium on Diabled Parking Permit, 2013.

\section{AUTHORS PROFILE}

Kohei Arai, He received BS, MS and PhD degrees in 1972, 1974 and 1982, respectively. He was with The Institute for Industrial Science and Technology of the University of Tokyo from April 1974 to December 1978 also was with National Space Development Agency of Japan from January, 1979 to March, 1990. During from 1985 to 1987, he was with Canada Centre for Remote Sensing as a Post Doctoral Fellow of National Science and Engineering Research Council of Canada. He moved to Saga University as a Professor in Department of Information Science on April 1990. He was a councilor for the Aeronautics and Space related to the Technology Committee of the Ministry of Science and Technology during from 1998 to 2000 . He was a councilor of Saga University for 2002 and 2003. He also was an executive councilor for the Remote Sensing Society of Japan for 2003 to 2005 . He is an Adjunct Professor of University of Arizona, USA since 1998. He also is Vice Chairman of the Commission "A" of ICSU/COSPAR since 2008. He wrote 30 books and published 442 journal papers 